\title{
Orfeo en Pausanias: entre el mito y la «diferencia»
}

\author{
José Marco Segura JAUBert \\ Universidad de Costa Rica \\ jm23jaubertair@hotmail.com
}

\section{RESUMEN}

La intención de este trabajo es revelar la visión de Pausanias acerca de un mito tan amplio y heterogéneo como es el de Orfeo, así como analizar cómo y por qué surge la noción de «diferencia» en el Periegeta relacionada con la figura mítica del bardo. Para establecer con claridad la posición de Pausanias en lo que respecta a las tradiciones atribuidas al cantor, se analizan aspectos como el origen de Orfeo, el aspecto que poseía, su leyenda, su carácter de mago y su relación con Museo y los Misterios de Eleusis.

Palabras clave: Mito, Orfeo, Pausanias, diferencia, Grecia.

\author{
Orpheus in Pausanias: \\ between myth and the «difference»
}

\begin{abstract}
The intention in this paper is analyze how and why Pausanias relate the difference with the mythic Orpheus. This will reveal another face of the vast myth of the bard. For this particular research some aspects of Orpheus myth will be studied: place of birth, appearance, legend, magician's role and his relation with Musaeus and the Eleusinian Mysteries.
\end{abstract}

Keywords: Myth, Orpheus, Pausanias, difference, Greece.

SUMARIO: 1. Introducción. 2. El origen de Orfeo. 3. El aspecto físico de Orfeo. 4. La leyenda de Orfeo. 5. Orfeo como mago. 6. Orfeo, Museo y los Misterios de Eleusis. 7. Conclusiones. 8. Bibliografía. 


\section{INTRODUCCIÓN}

Pausanias, de igual manera que la mayoría de los griegos en la Antigüedad, veía con mucho recelo las tradiciones que no pertenecían a su entorno ${ }^{1}$, por temor a lo diferente, a lo que es distinto y ajeno. De acuerdo con la Metafisica ${ }^{2}$ de Aristóteles se entiende que dentro de los géneros se determinan individuaciones por sus diferencias. A cada individuo le corresponden géneros y diferencias, no obstante, su individualidad máxima -aquello que lo hace ser sí mismo- es la diferencia última.

La noción de «diferencia» llevada en paralelo a distintos ámbitos como el cultural, el social, el filosófico y el religioso, puede formar parte integral de la comprensión de una persona, ya que es el individuo mismo el que asume un rol en relación a otros personajes de su propia cultura, como parte de un proceso de reacción que no tiene por qué estar relacionado con la estigmatización o la condena.

Con esta idea clara conviene revisar de manera detenida la actitud que presenta Pausanias respecto a las tradiciones que se atribuyen al bardo Orfeo, que si bien es un personaje griego, no es del entorno del Periegeta.

Antes de analizar los pasajes que dedica el Periegeta a Orfeo en su Descripción de Grecia, es necesario tener en cuenta la posición que mantenían los griegos con respecto a personajes, mitos y leyendas que no pertenecían a su ámbito local.

\section{EL ORIGEN DE ORFEO}

El lugar de origen que atribuyen a Orfeo los autores antiguos son las zonas al norte de Grecia. Así Estrabón sostenía que Orfeo era un cicón, parte de una tribu que se encontraba establecida entre el río Axio y el Hebro, y que había vivido en $\mathrm{Dio}^{3}$ (Macedonia); los poetas alejandrinos indican el monte Rodope ${ }^{4}$ (entre Tracia y Macedonia) y también la zona de Bistonia ${ }^{5}$, todas regiones del norte de Grecia, además de Pimplea, ciudad de Pieria ${ }^{6}$, como su lugar de origen.

El primer aspecto donde se puede observar la «diferencia» de acuerdo a Aristóteles, y llevada al ámbito cultural, aparece en el Libro IX cuando Pausanias indica el

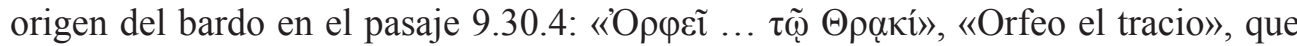
circunscribe la figura del poeta a la zona de Tracia, región al norte de Grecia.

Cabe destacar que Pausanias señala el origen del poeta en su recorrido por la zona de Beocia; así expone que Orfeo es diferente del resto de personajes de los que habla en su relato.

${ }^{1}$ Martín Hernández 2010, 18.

2 Arist. Metaph. 1038a.

${ }^{3}$ Str. 7 fr. 18 (fr. 554, 659, 816 B.; T 40 K.). También veáse: Ps.-Arist. Peplus (p. 403 Rose), Verg. G. 4 520, Ou. Met. 11. 3.

${ }^{4}$ Pomp. Mela 2. 17 y 2. 28; Verg. Buc. 6. 30.

${ }^{5}$ A.R.1.34 y 2. 703s; Ou. Pont. 2.9, 53s.

${ }^{6}$ A.R.1.25. 


\section{EL ASPECTO FÍSICO DE ORFEO}

La «diferencia» cultural de Orfeo, y que el Periegeta conoce y pone de manifiesto en sus escritos, se amplifica por el aspecto físico que debería poseer el cantor, cuando observa la figura del músico en la lesque de Polignoto en Delfos:

Mirando de nuevo hacia la parte de abajo de la pintura, a continuación, después de Patroclo, está Orfeo sentado como en una colina, y sostiene una cítara en la mano izquierda, y con la otra mano toca un sauce [hay ramas que toca y está apoyado en el árbol]. Parece que es el bosque sagrado de Perséfone, donde crecen álamos negros y sauces, según cree Homero. Orfeo tiene aspecto griego, y ni su vestido ni lo que le cubre la cabeza es tracio.

En el mismo sauce, por el otro lado, se reclina Promedonte. Hay quienes creen que el nombre de Promedonte ha sido introducido en la poesía por Polignoto. Otros dicen que fue un griego que gustaba de escuchar toda clase de música, y especialmente el canto de Orfeo.

En esta parte de la pintura está Esquedio, el que condujo a los focidios a Troya, y después de él está Pelias sentado en un trono, con la barba y el cabello igualmente canosos. Está mirando a Orfeo. Esquedio tiene un cuchillo y una corona de grama. Támiris, que está sentado muy cerca de Pelias, está ciego y tiene un aspecto del todo lamentable, con una gran cabellera y mucha barba. La lira está tirada a sus pies, sus brazos están rotos y las cuerdas desgarradas?

Olmos sostiene que Pausanias se sorprende por el aspecto de Orfeo, debido a que la imagen que se tenía del bardo en su época era distinta, y que probablemente el Periegeta esperaba toparse con un personaje con atuendo oriental y exótico, como se impondrá a partir del s. IV a.C. Dicha representación griega indica un Orfeo educador en torno a quien las miradas de los hombres se centraban ${ }^{8}$. Además, este autor señala que la rama que sostiene el bardo es el instrumento de la inspiración poética, y el árbol sobre el que se recuesta parece ser el bosque de Perséfone ${ }^{9}$, interpretación que está basada en un pasaje de Homero $^{10}$.

Si bien se puede dar esta propuesta como válida, se estima que los campos dedicados a la diosa remiten más a un paisaje terrenal que a uno del inframundo como lo quiere indicar Olmos. Pienso que la imagen de Orfeo allí indica que dicho personaje murió. No aparece nunca una escena del descenso del bardo pese a que el contexto apunte a una catábasis.

Se debe agregar también que ante todo, se aprecian en el pasaje de Pausanias tres cosas. En primer lugar, el asombro cultural de parte de Pausanias hacia la represen-

\footnotetext{
${ }^{7}$ Paus. 10.30.6-8. Traducción de Herrero Ingelmo 1994, 428-429.

${ }^{8}$ Olmos, 2008, 154.

9 También coincide con esta afirmación Linforth 1973, 30.

10 Od.10.509-510.
} 
tación de Orfeo, porque el bardo, al ser un héroe venido de Tracia, presenta rasgos semejantes a las personas con las que el Periegeta convivía a diario. En segundo lugar, el creciente interés de los griegos por las peculiaridades que venían de lugares alejados en ese momento histórico ${ }^{11}$. Por último, la adopción de una figura mítica como Orfeo a través de contactos culturales, lo que puede indicar una transformación $^{12}$ en la forma de pensar de los griegos. Lo que Pausanias consideraba «lejano», se ha tornado «cercano».

Ello se debe a que Orfeo no se rige por las leyes de la polis, sino que las trasciende, está y no está en ella debido a su fama como fundador de unos misterios que eran escondidos a la luz pública ${ }^{13}$. Orfeo como tal, se encuentra en el «afuera» y en el «adentro», entre el mundo de los vivos y el mundo de los muertos.

Se asiste entonces a un juego de dobles, con Pausanias, por un lado, que se debate entre sus tradiciones y modo de pensar distanciado de personajes alejados de su entorno, y con Orfeo, por otro lado, que está a la vez circunscrito y no circunscrito al contexto del Periegeta. Orfeo es considerado griego por Pausanias, pero diferente en tanto en cuanto proviene de un lugar distante.

Para Pausanias por una parte, ese «caos» asociado a lo «desconocido», a lo «lejano», se pudo haber convertido en parte del «orden» imperante, y por otra parte, significa para él aceptar a un personaje lejano como si fuera uno de los suyos. Orfeo, un personaje que trasciende las leyes de la polis, aunado a unos rasgos griegos asignados por Polignoto, podría sugerir que cualquier griego podía trascender las leyes de esa sociedad, lo que implicaría que, un griego cualquiera del entorno de Pausanias que tuviera empatía por los textos que se atribuían al cantor, podría sentir esta imagen más cercana por apropiación y actuar en consecuencia, cosa no bien vista en esa época.

Esta idea encaja perfectamente al observar la negativa visión que presenta Estrabón (autor contemporáneo de Pausanias) sobre Orfeo y sus seguidores, como se verá en el siguiente apartado.

\section{LA LEYENDA DE ORFEO}

La «diferencia» cultural que se advierte en Pausanias en relación a la figura del bardo, se observa de igual manera en lo que respecta a las tradiciones que se le atribuyen a Orfeo.

Junto a Orfeo el tracio está esculpida Teleté, y alrededor de él hay animales en piedra y bronce oyéndole cantar. Entre otras muchas cosas que no son verdad y que los griegos creen, está que Orfeo era hijo de la musa Calíope y no de la hija de Piero y que los animales le seguían seducidos por su canto, y él fue vivo al Hades

\footnotetext{
${ }^{11}$ Graf, 1987, 106.

12 Burkert, 1983, 119.

${ }^{13}$ Freiert, 1991, 37.
} 
a pedir a su mujer a los dioses subterráneos. Orfeo, en mi opinión, superó a sus predecesores por la belleza de sus versos y alcanzó gran poder, porque se creía que había descubierto misterios de dioses, purificaciones de impiedades, curaciones de enfermedades y medios de alejar la cólera divina ${ }^{14}$.

Al leer este texto se nota que Pausanias tiene una actitud reservada en cuanto al bardo y los hechos que se le atribuyen, por la expresión que usa antes de entrar a

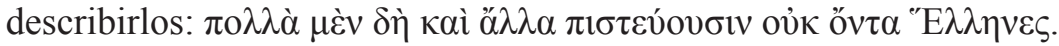

Es de destacar que la «diferencia» vuelve a desempeñar un papel preponderante, ya que no solo se aprecia la distancia cultural del autor con las creencias en torno a Orfeo, sino que Pausanias plantea una «diferencia» social entre él y otros griegos ( $\left.{ }^{\prime \prime} \mathrm{\perp} \lambda \eta v \varepsilon \varsigma\right)$.

Considero que dicha distancia posee dos niveles: uno, el cultural, como se observa claramente en el apartado anterior; y dos, el ideológico, esto es claro porque Pausanias es griego, pero a la vez no piensa como muchos de sus coterráneos, quienes creen en las tradiciones del bardo.

El Periegeta no solo expone su distancia cultural y filosófica, sino que describe una parte de la realidad del momento histórico: existían seguidores de Orfeo y de sus tradiciones en el s. II de nuestra era; pese a esto, el término "E $\lambda \lambda \eta v \varepsilon \varsigma$ es demasiado general para poder definir concretamente quiénes eran. Solo queda decir que se encontraban por las zonas que Pausanias transitaba, pero él no se identifica con ellos en este rubro.

En cuanto al distanciamiento filosófico que presenta Pausanias con respecto a las tradiciones atribuidas a Orfeo, se debe a que el Periegeta es deudor del evemerismo, corriente de pensamiento que apareció en Grecia en el siglo IV a.C. y que se extendió posteriormente por el Imperio Romano. Se trata de una teoría hermenéutica de la interpretación de los mitos creada por Evémero de Mesene (s. IV a.C.), de la que solo se cuenta con resúmenes. Dicha forma de interpretación dice que los dioses no son más que personajes históricos con un pasado mal recordado, y magnificados por una tradición legendaria. El sentido oculto de los mitos es de naturaleza histórica y social.

El concepto de «diferencia» llevada a los ámbitos político y social también aparece en Estrabón al referirse a la leyenda de Orfeo:

Allí (i. e. en Dío) dicen que vivió Orfeo el cicón, un hechicero que al principio vivía mendigando de su música, de la adivinación y de los ritos orgiásticos de las teletai, pero después se creyó merecedor de cosas mayores y se procuró seguidores y poder. Algunos lo aceptaron voluntariamente, pero otros sospechando un complot y violencia, se unieron contra él y lo mataron ${ }^{15}$.

Entre este pasaje de Estrabón y el pasaje 9.30.4 de Pausanias, se encuentran semejanzas y diferencias que vale la pena resaltar en este breve estudio:

\footnotetext{
14 Paus. 9.30.4. Traducción de Herrero Ingelmo, 1994, 304.

15 Str. 7 fr. 18 (fr. 554, 659, 816 B.; T 40 K.). Traducción de Vela Tejada, 2001, 327.
} 
- Tanto Pausanias como Estrabón comparten una concepción evemerista del mito de Orfeo.

- El origen de Orfeo en ambos pasajes remite a lugares alejados, pero Pausanias lo ubica en Tracia como la gran mayoría de autores, mientras que Estrabón señala que es de Cicón.

- Ninguno de los dos se hace eco de la tradición que liga a Orfeo con Apolo, ni lo ven como un filósofo. Tampoco hacen mención de la tradición de la cabeza de Orfeo y su llegada a Lesbos, rasgos todos ellos habituales en otros autores de su época.

- En ambos autores se observa el concepto de «diferencia»: Pausanias distanciado cultural y filosóficamente; Estrabón está un paso más allá de Pausanias, ya que utiliza este distanciamiento para atacar y desprestigiar a un grupo de personas y a su figura religiosa.

- La descripción de Estrabón es totalmente negativa hacia la figura del bardo y sus seguidores, probablemente porque los consideraba muy peligrosos para las instituciones político-sociales de la época. Pausanias, por su parte, tiene aprecio por la literatura que se atribuía a Orfeo y, en cuanto al rol del cantor como fundador de ritos y misterios, pese a que niega dicha función, mantiene un respeto hacia estas tradiciones por ser parte de su pueblo, tradiciones que él pretendía enaltecer de alguna manera con su descripción, y así de igual forma, mostraba respeto a quienes profesaban dicha creencia.

- Estrabón suprime rasgos de la leyenda de Orfeo que aparecen en numerosas fuentes. Omite que el cantor sea hijo de la Musa Calíope, su condición de Argonauta, que es uno de sus rasgos más antiguos, y el hecho más notable dentro de la mitología de Orfeo: su descenso al Hades en busca de su amada. Mientras que Pausanias menciona el mito del descenso y que es hijo de Musa, mas niega su veracidad; tampoco habla de la condición de Argonauta de Orfeo.

- Estrabón no hace referencia a la esposa de Orfeo, mientras que Pausanias omite su nombre: Eurídice ${ }^{16}$.

Platón, por su parte, se adelantó a Pausanias y Estrabón en cuanto a su distancia con Orfeo, mas no utilizó nunca el concepto de «diferencia», cuando criticaba de manera drástica a los orfeotelestas, y por ende a Orfeo, en sus escritos, como por ejemplo en el siguiente pasaje de La República.

Charlatanes y adivinos, yendo a las casas de los ricos, los persuadían de que tenían un poder procedente de los dioses mediante sacrificios y encantamientos de curar con placeres y fiestas la injusticia cometida por uno mismo o por un antepasado. Y si alguien quiere hacer daño a un enemigo, tanto sea justo como

\footnotetext{
${ }^{16}$ Similar a la primera referencia literaria que poseemos de este mito en E. Alc. 357-362.
} 
injusto, a cambio de una pequeña remuneración, le perjudicarán con encantamientos y nudos mágicos, persuadiéndolos, según ellos mismos dicen, de que los dioses les obedecen. De todas estas palabras ponen a los poetas como testimonios. (...) Presentan un montón de libros de Orfeo y Museo, descendientes, según dicen, de la Luna y de las Musas, según los cuales realizan sacrificios, persuadiendo no sólo a los particulares, sino también a ciudades enteras, de que existen liberaciones y purificaciones de las injusticias...que denominan iniciaciones $^{17}$.

Así también en el siguiente pasaje de Las Leyes:

Cuantos de aquellos que, parecidos a las fieras, al no creer en los dioses o al pensar que éstos son negligentes o maleables con plegarias y desdeñando a los hombres sedujesen a muchos de los vivos afirmando que conducen las almas de los muertos y prometiendo que persuaden a los dioses porque los encantan con sacrificios, súplicas y encantamientos y que por causa del dinero intentasen arruinar completamente a particulares, familias enteras y ciudades ${ }^{18}$.

Al comparar el pasaje 9.30.4 del Periegeta, con los que le dedican Estrabón y el filósofo Platón a Orfeo, se puede ver lo siguiente:

- Platón se acerca muchísimo a la visión que nos da Estrabón, ya que se refiere a Orfeo de forma negativa ${ }^{19}$.

- Platón, igual que Pausanias, no cree que el bardo sea hijo de una Musa, a la que nunca menciona por su nombre, y solo se refiere a ella en forma alusiva, crítica o irónica.

- Tanto en Pausanias como en Estrabón se usa la «diferencia» como mecanismo para distanciarse de dichas creencias. Platón antecede de cierta forma al concepto de su discípulo, y se acerca más al pensamiento de Estrabón, para desprestigiar una manera de enseñar que consideraba equivocada, y no con un afán político-social como lo planteaba Estrabón.

- Platón sostiene que la manera de enseñar de Orfeo es engañosa y perjudicial, de modo semejante a lo que dice Estrabón, lo presenta como un cobarde, al no morir por su amada; Pausanias, al respecto, se mantiene al margen. Sin embargo, la actitud de Platón se distingue de la Estrabón, en que el filósofo mira a Orfeo como un competidor directo dentro del campo de la Paideia, considera su método nocivo ${ }^{20}$. Estrabón solo lo mira como un mal social.

\footnotetext{
${ }^{17}$ Pl. R. 364b. Traducción de F. Casadesús, «Orfeo: el poder encantador de la música y la palabra», http:// www.liceus.com/cgi-bin/aco/culc/mit/08400.asp [acceso: 24.10.2012].

18 Pl. Lg. 909a. Traducción de F. Casadesús, «Orfeo: el poder encantador de la música y la palabra», http:// www.liceus.com/cgi-bin/aco/culc/mit/08400.asp [acceso: 24.10.2012].

19 Pl. Symp. 179d.

20 Bernabé, 2010, 249 y ss.
} 
Otro contemporáneo de Pausanias es el mitógrafo Apolodoro, autor de la Biblioteca, quien da una versión más estándar del mito del bardo:

De Calíope y de Eagro, pero nominalmente de Apolo, nacen Lino, al que dio muerte Heracles, y Orfeo, quien se ejercitó en el arte de la cítara y cuando cantaba movía piedras y árboles. Al morir Eurídice, su esposa, mordida por una serpiente, descendió al Hades queriendo traerla de vuelta y convenció a Plutón para que la dejara volver. Él accedió a hacerlo si Orfeo no se volvía por el camino hasta llegar a su casa; pero él, desconfiado, se dio la vuelta para mirar a su mujer y ella volvió atrás. Orfeo introdujo los misterios de Dioniso y fue enterrado cerca de Pieria, tras haber sido desmembrado por las ménades ${ }^{21}$.

Bernabé establece una serie de rasgos que presenta el texto de Apolodoro, que permite una comparación entre éste y el 9.30.4 del Periegeta ${ }^{22}$ :

- Apolodoro se limita al aséptico papel escolar de un mitógrafo: no trata de poner en duda la veracidad de las tradiciones, sino simplemente las recopila y elabora un relato lo más unitario posible, una especie de «mínimo común múltiplo» de los rasgos de su leyenda que presentan las fuentes más antiguas. Pausanias da una versión modernizada y evemerista del mito del bardo.

- El mitógrafo evita relacionar a Orfeo con realidades contemporáneas o simplemente del mundo de lo real, caso contrario a Pausanias y principalmente a Estrabón.

- Apolodoro no da cabida a lo que se podría llamar «episodios turísticos», relacionados con ciudades que pretendían contar con presuntas tumbas de Orfeo y referían grandes prodigios sobre ellas para atraer visitantes. Estrabón expone el lugar de muerte del bardo, mas no señala que exista una tumba, ya que no ve a Orfeo como un héroe. En Pausanias si aparecen dos ejemplos del lecho de muerte del poeta:

Los macedonios que habitan la región de Pieria al pie del monte y la ciudad de Dío dicen que allí tuvo lugar la muerte de Orfeo a manos de las mujeres. Yendo desde Dío por el camino hacia el monte, y avanzando veinte estadios, hay una columna a la derecha, y encima de la columna hay una hidria de piedra que contiene los huesos de Orfeo, según dicen los del lugar ${ }^{23}$.

He oído también otra leyenda en Larisa: que en el Olimpo hay una ciudad, Libetra $^{24}$, en la parte del monte que mira a Macedonia, y que no lejos de la ciudad está el sepulcro de Orfeo. A los de Libetra les vino un oráculo de Dioniso desde Tracia diciendo que, cuando el sol viera los huesos de Orfeo, la ciudad de Libetra

\footnotetext{
21 Apollod. 1.3.2. Traducción de Bernabé, 2013, 1.

22 Bernabé, 2013, 8 y ss.

23 Paus. 9.30.7. Traducción de Herrero Ingelmo, 1994, 305.

24 Ciudad próxima al Olimpo.
} 
sería destruida por un jabalí. Ellos no tuvieron muy en cuenta el oráculo, porque pensaban que no había un animal tan grande y fuerte como para destruir su ciudad, y que un jabalí tenía más audacia que fuerza.

Pero cuando al dios le pareció bien les sucedió lo siguiente: aproximadamente a mediodía, un pastor, reclinándose sobre la tumba de Orfeo, se quedó dormido, y mientras dormía le aconteció que cantó los versos de Orfeo con una voz alta y dulce. Entonces, los que estaban pastoreando o labrando la tierra muy cerca, dejando sus labores, se congregaron para oír el canto del pastor en su sueño; y al empujarse unos a otros y reñir por estar más cerca del pastor derribaron la columna, la urna se rompió al caerse de ella y el sol vio lo que quedaba de los huesos de Orfeo.

Al punto, a la noche siguiente, el dios derramó mucha agua del cielo, y el río Sis, que es uno de los torrentes de los alrededores del Olimpo, echó abajo las murallas de Libetra, derribó santuarios de dioses y casas de hombres, y ahogó a los hombres e igualmente a todos los seres vivos de la ciudad. Cuando los de Libetra estaban ya arruinados, los macedonios de Dío, según el relato de un extranjero de Larisa, llevaron los huesos de Orfeo a su ciudad ${ }^{25}$.

- Apolodoro no tiene que ver con las $\tau \varepsilon \lambda \varepsilon \tau \alpha i ́$ ni con los orfeotelestas, adivinos o farsantes de diversa condición que, todavía en su tiempo, prometían curación, salvación o felicidad. Tampoco tiene que ver con la poesía que circulaba atribuida a Orfeo, ni con los inventos que pasaban por ser suyos. Pausanias, pese a que no cree en estas tradiciones, las menciona. De igual forma Platón y Estrabón no solo hacen mención de ellas, sino que las degradan.

- Apolodoro trata de desvincular todo lo posible a Orfeo de las actividades de su época que se relacionan de un modo u otro con él: los oráculos, la magia, la medicina o la literatura. En su presentación, Orfeo pertenece al mundo lejano del mito, personaje literario que no debe confundirse con las personas existentes en la realidad, ni interpretarse en términos evemeristas o modernizados. En el caso de Pausanias y Estrabón ocurre lo contrario.

Aparte de estos cinco puntos se pueden establecer más comparaciones útiles para este análisis:

- Pausanias y Estrabón utilizan la «diferencia», independientemente de su ámbito, como mecanismo para distanciarse de las tradiciones atribuidas a Orfeo. Platón, se anticipa a dicho concepto, mientras que Apolodoro se abstiene de ello.

- Los tres autores le asignan un origen lejano a Orfeo. Apolodoro no brinda ese dato.

- Pausanias y Estrabón nunca mencionan el episodio de Orfeo como Argonauta, cosa que si hace Apolodoro ${ }^{26}$.

\footnotetext{
25 Paus. 9.30.9. Traducción de Herrero Ingelmo, 1994, 305-306.

26 Apollod. 1.9.25.
} 
- El Periegeta no expone tampoco la relación del cantor con Apolo o que tenía por hermano a $\mathrm{Lino}^{27}$, como sí lo hace el mitógrafo.

- Pausanias y Apolodoro no mencionan el episodio de la cabeza de Orfeo ni su posterior viaje a Lesbos; tampoco ellos dicen nada acerca de los remedios para curar enfermedades o salvarse en el otro mundo que -como indica Platón- los farsantes y adivinos atribuían a Orfeo.

El distanciamiento entre Pausanias y las tradiciones atribuidas a Orfeo, se puede notar en varios de sus pasajes con formas verbales como $\lambda \dot{\varepsilon} \gamma \varepsilon \tau \alpha l$ (9.17.7), $\lambda \dot{\varepsilon} \gamma o v \sigma \mathrm{l}$ (9.30.6), $\lambda \dot{\varepsilon} \gamma o v \tau \varepsilon \varsigma$ (2.30.2), $\lambda \dot{\varepsilon} \gamma o v \sigma ı v ~(3.13 .2), \varphi \alpha \sigma ı v$ (3.20.5, 9.30.7), $\varphi \alpha \sigma \mathrm{l}$ (9.30.5).

Hacia el final del pasaje 9.30.4, el Periegeta utiliza ठокєĩv, lo que refleja la distancia que asume el autor, ante las tradiciones que se refieren a los poderes que se le atribuían a Orfeo, para descubrir los misterios de los dioses, purificaciones de impiedades y medios de alejar la cólera divina.

Conviene destacar que frente a la imagen que le presenta la tradición a Pausanias, el Periegeta piensa que Orfeo existió y que era un hombre de poder, proveniente de un linaje de reyes. En este pasaje es patente la «diferencia» cultural y filosófica que toma Pausanias en cuanto a la figura de Orfeo, sus tradiciones y sus seguidores; «diferencia» que también es asumida por otros autores con posturas semejantes, pero entre unos y otros se pueden encontrar diversos matices, como ya se señaló.

Se puede advertir que a lo largo de varios siglos, desde Platón en el s. V a.C. al s. II de nuestra era, ya se ponían en tela de juicio los hechos significativos del mito de Orfeo. Sin embargo, se creía tanto en la existencia del bardo siglos antes de Homero como en su relación con los misterios.

La fama del poeta como educador de hombres no era bien vista por Platón, ya que aquellos que decían seguir sus enseñanzas eran tildados de embaucadores y engañosos por varios autores. En este caso, se puede afirmar que aquella figura mítica de la que se dice que bajó al Hades por su amada, y fue pieza importante de la aventura de los Argonautas, se volvió reflejo de los que deambulaban como sus fieles en la Grecia antigua a lo largo de siete siglos.

\section{ORFEO COMO MAGO}

El concepto de magia se ha asociado a lo desconocido desde su aparición en Grecia. Muchas culturas han utilizado este vocablo para designar las prácticas religiosas de otros pueblos, sin embargo las nociones de «magia» entre un pueblo y otro, raramente coinciden en cuanto a los detalles que el término implica; la distinción específica del término comienza a aparecer desde finales de la Edad Media y principios de la era moderna ${ }^{28}$, donde también era común el uso de conceptos

\footnotetext{
27 Para Lino véase Martínez Nieto, 2008, 560 y ss.

28 Bremmer, 1999, 11.
} 
como «demoniaco» o «satánico» para designar a aquellas prácticas no cristianas. La creación de roles positivos y negativos provee una noción de legitimidad; el pensamiento binario permite encasillar de una manera fácil a una amplia población, lo que a todas luces es necesario para la perspectiva política de un gobierno que busca dominar su entorno. No hay espacio para el término medio, la persona o está «dentro» o está «afuera», ir más allá implica una ampliación de los conceptos de lo «bueno» y lo «malo», de lo «ético» o «no ético», que tendría como consecuencia una visión más amplia de la sociedad, en cuanto a una realidad humana en la que los estilos de vida serían diversos, cosa no conveniente para regímenes autoritarios que miran esta diversidad como «caos».

Durante la Antigüedad el conocimiento religioso «verdadero» fue forzado a adaptarse a nuevas condiciones político-sociales, en al menos cinco ocasiones en Grecia y Roma:

a) La formación de las ciudades-estado al comienzo del período arcaico.

b) El paso de ciudades-estado independientes a los reinos helenísticos.

c) El surgimiento del Principado.

d) La crisis del s. III a.C. que llevó a la Tetrarquía.

e) En el s. IV d.C., la transición de Roma a un Imperio Cristiano.

En cada uno de estos procesos se establecieron nuevas concepciones de lo que se consideraba conocimiento religioso «verdadero». Ello llevó a la creación de imágenes de lo que se estimó como «falso» o «no legítimo» en cada ocasión. Estos cinco períodos históricos fueron particularmente productivos en la creación de imágenes sociales que se encontraban en clara relación con el establecimiento de la «nueva» moral ${ }^{29}$. Una de estas imágenes falsas era la magia.

El término magia se ha definido siempre por oposición al de religión, pero cabe destacar que en la Antigüedad no existía un límite claro entre lo que se consideraba medicina, lo milagroso y lo mágico ${ }^{30}$. En lo que concierne a Grecia y Roma el conocimiento religioso «verdadero» consistía en conocer el panteón de dioses, y participar de manera activa en cada una de las festividades cívicas dentro del calendario anual. Todos aquellos cultos que no partían de esta norma central eran en alguna medida problemáticos. Esto no solo funcionaba para que las personas definieran su espacio político, sino también para que su lugar en la sociedad los convirtiera en ciudadanos.

El conocimiento religioso «no legítimo» es más plausible encontrarlo tanto entre los individuos que no son ciudadanos como en aquellos que no son varones: las mujeres $^{31}$, lo que plantea no solo un problema de índole religiosa, sino también de género. Así como indica Gordon, el conocimiento religioso «verdadero» tiene como

\footnotetext{
29 Gordon, 1999, 192.

30 Padilla, 1997, 141.

31 Gordon, 1999, 193-194.
} 
función definir quiénes pertenecen a determinada ciudad o gremio y quiénes de alguna manera no lo hacen ${ }^{32}$.

$\mathrm{La}$ «magia» es definida por Smith como lo indeterminado, impersonal o colectivo, lo externo, el tabú y lo que está relacionado con el miedo (evasión o precipitación); mientras que la «religión» es lo diferenciado, lo personal o individual, lo interno, lo ético y lo que posee relaciones de reverencia (sumisión o petición) ${ }^{33}$.

Indica Martín Hernández que un ejemplo claro de esta distinción se puede observar en el desarrollo semántico del término iranio «mago» ${ }^{34}$. Al comienzo este término era utilizado por los griegos para designar a los sacerdotes persas, pero ya en el s. IV a.C. pasó a ser un sustantivo peyorativo, que calificaba a quienes realizaban acciones rituales opuestas a las ceremonias religiosas oficiales. Así, el mago fue asociado con farsantes, hechiceros y envenenadores.

En un pasaje del tratado médico Sobre la enfermedad sagrada de finales del s. V a. C. o principios del s. IV a.C. atribuido a Hipócrates, se sostiene que el mago es aquel que realiza purificaciones, magia y todo tipo de charlatanerías; en resumidas cuentas, es aquel que práctica técnicas de sanación comparables a las de los purificadores y sacerdotes que oran, pero que poseen un conocimiento teológico y cosmológico inferior ${ }^{35}$.

De acuerdo con Heródoto los magos poseían el poder de interpretar los sueños ${ }^{36}$ y los eclipses ${ }^{37}$, y eran indispensables para libaciones ${ }^{38}$ y sacrificios ${ }^{39}$ donde cantaban una teogonía ${ }^{40}$. Pese a ello, el historiador los describe como criaturas molestas ${ }^{41}$. El cantar una teogonía durante un ritual está relacionado con las tradiciones que ponen en contacto a la figura de Orfeo con la fundación de los misterios de Eleusis, donde se decía que él o Museo cantaron una teogonía ${ }^{42}$. Como se observa el ser calificado como «mago» envolvía varias de estas características, todas distintas, lo que también refleja la heterogeneidad del término y la poca claridad que se tenía sobre lo que implicaba en la Antigüedad.

Pausanias no es ajeno a esta manera de ver el mundo y señala que el bardo Orfeo es para él un mago. Esta forma de percibir al cantor la indica Pausanias en su trayecto por la zona de Élide. Además, el Periegeta escribe sobre Anfión a quien considera un mago igual que Orfeo ${ }^{43}$.

\footnotetext{
32 Gordon, 1999, 194.

33 Smith, 1978, 431.

34 Martín Hernández, 2010, 18-19.

${ }^{35}$ Hp. Morb. Sacr. 18. 6 (90 Grenseman, OF 657 I), Bremmer, 1999, 4.

${ }^{36}$ Hdt. 1.107-8, 120, 128; 7.19.

37 Hdt. 7.37.

38 Hdt. 7.43.

${ }^{39}$ Hdt. 7.113-4, 191.

${ }^{40}$ Hdt. 1.132.

41 Hdt. 1.140.

42 Para Orfeo: Heraclit. 22 B 14 D.-K., Hdt. 2.51.3, IG XII 5.444 A 25 (FGrHist 239 A, ep. 14; OF 379), P Berol. 44. También: Thdt. Affect. 1.21 (Kern Test. $103=$ OF 51) y Procl. in R. 2.310.16 Kroll (Kern Test. 102 $=$ OF 517 I), Pau. 3.13.2 y 3.14.5. Para Museo: D. S. 4.25.1.

43 Paus. 6.20.18 y 9.17.7. Para una comparación entre Orfeo y Anfión véase Macías, 2008, 504 ss.
} 
Este egipcio pensaba que Anfión y el tracio Orfeo eran expertos magos y que con sus cantos las fieras venían a Orfeo y las piedras venían a Anfión para construir murallas $^{44}$.

El Periegeta indica que en su época Orfeo era identificado como mago. Martín Hernández sostiene que el canto del poeta se consideraba mágico, lo que daba como resultado que al bardo se le mirara como un ser poderoso ${ }^{45}$.

Realmente Pausanias lo que expresa es el pensamiento de un egipcio y nunca el

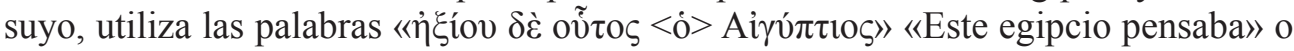
«Este egipcio creía», distanciándose él de la opinión del hombre proveniente de la tierra de los faraones. Esta expresión puede ponerse en relación con lo que dice en

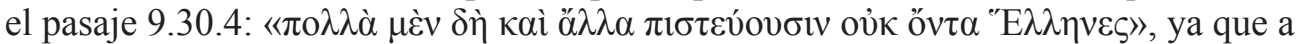
continuación de esta frase están los hechos de Orfeo que lo relacionan con la magia y que Pausanias expresamente niega.

El uso del término «mago» puede indicar normalmente una acusación concerniente al tipo de actividades religiosas que se le atribuían al poeta, y que no son parte de la posición del Periegeta. Pueden implicar además, una reducción de la teología y cosmogonía del bardo a la categoría de «falsa» religiosidad.

Es importante recalcar que el grupo de creyentes en la figura del cantor no solo era griego, sino que podían ser de distintos países, en este caso un egipcio. Que sea un egipcio el que se refiera a Orfeo no debe de causar ninguna extrañeza, debido a que existía una tradición que al parecer procede del historiador Hecateo de Abdera, que vivió entre los s. IV y III a.C., y que recoge Diodoro Sículo, donde se cuenta el viaje del bardo a la tierra de los faraones:

Cuentan los sacerdotes de los egipcios que según sus registros en los escritos sagrados llegaron junto a ellos en los tiempos antiguos Orfeo, Museo, Melampo y Dédalo. Tras haber aprendido los mitos acerca de los dioses, (sc. Orfeo) viajó a Egipto y allí, luego de haber añadido nuevos conocimientos a los suyos, se convirtió en el más ilustre de los griegos en cuanto a teología, rituales, poemas y música ${ }^{46}$.

Es de destacar que Diodoro indica que entre estos conocimientos adquiridos por Orfeo estaba la magia ${ }^{47}$. El siciliano es al parecer el único autor «pagano» que hace eco de esta tradición, mientras que autores cristianos hacen uso frecuente de esta noticia de Diodoro ${ }^{48}$. Según Bernabé, la tradición del viaje a Egipto parece deberse a que se ajustaba con la idea apologética de que la religión órfica proce-

44 Pau. 6.20.18. Traducción de Herrero Ingelmo, 1994, 357.

45 Martín Hernández, 2008, 199.

46 D.S. 4.25.3. Traducción de Bernabé, 2008, 900.

47 D.S. 1.23 .2 y $6 ; 1.69 .4 ; 1.92 .3 ; 1.96 .2$ s.

${ }^{48}$ Eus. PE 1.6.4 (OF 52 III), Iust. Phil. Coh. Gr. 15. También Epiph. Haer. 1.182.13 y Thdt. Affect. 1.21, 1.144, 12.1. 
día en último término de Moisés, pero se habría visto «degradada» por el profeta tracio $^{49}$.

Esta tradición es completamente ignorada por Pausanias, quien no habla de la referencia antigua de Heródoto sobre las semejanzas entre prácticas órficas y egipcias $^{50}$. Tampoco menciona los ritos iniciáticos y las celebraciones orgiásticas que llevó Orfeo a Grecia tras su estancia en las tierras del Nilo ${ }^{51}$. Tampoco indica que Caronte y otros elementos de la escenografía órfica del más allá proceden de Egipto ${ }^{52}$. Pausanias no hace mención de un ritual egipcio como modelo posible para una descripción órfica del más allá ${ }^{53}$. Asimismo Pausanias elude el hecho de que algunos mitólogos griegos identificaban a Osiris con Dioniso ${ }^{54}$. Tampoco habla sobre las obras literarias órficas como el Relato sacro Egipcio, del que se tiene noticia por dos pasajes que el autor de las Argonáuticas Órficas rememora en sus poemas ${ }^{55}$. Se observa así el casi nulo interés que tenía Pausanias por los rituales, creencias y literatura órfica, y más cuando estas tradiciones estaban asociadas a tierras que no eran la suya.

La negativa visión de la «magia» va asociada a cosas que se encuentran en los límites: lo «caótico», lo «rebelde», lo «distante», «lo diferente», y está relacionada con lo que no está en su lugar de origen: lo «híbrido», lo «adyacente». Estas etiquetas hacen a las sociedades más seguras y conscientes de sí mismas, lo que son y lo que no son, lo que las hace menos vulnerables y susceptibles a lo que venga de fuera. No es un problema de sustancia lo que se enfrenta, lo que hay de fondo es un problema de taxonomías relativas al lugar en que se vive, que al ser llevadas en paralelo al ámbito religioso muestran concordancias con la «ambivalencia de lo Sagrado» o la distinción entre «religión» $\mathrm{y}$ «magia».

Smith sostiene que esta forma de comprender las cosas es meramente una categoría etnográfica, sin embargo dicho pensamiento enfocado desde una perspectiva más activa conduce a reconocer lo que es «extraño», ya sea un enemigo extranjero o un hereje, se «civiliza» al «incivilizado» ${ }^{56}$, como ya se indicó anteriormente con respecto a la sorpresa de Pausanias al encontrarse la imagen de Orfeo con aspecto de griego en la lesque de Polignoto.

No solo en el pasaje 6.20.18 analizado anteriormente se indica por parte del Periegeta que Orfeo es un mago; en su relato por la zona de Tebas, nuevamente Pausanias muestra esta característica cuando engarza el relato de Anfión con el del bardo:

\footnotetext{
49 Bernabé, 2008, 901.

${ }^{50}$ Hdt. 2.123 (OF 423).

51 D. S. 1.96.3.

52 D. S. 1.92 .3

53 D. S. 1.97 .1 ss. (OF 62).

54 D. S. 1.11.2.

55 AO 32 (OF 41) y 43-45 (OF 40).

56 Smith, 1978, 427-428.
} 
Las piedras que hay junto al sepulcro de Anfión, que han sido puestas debajo ***57 y en general no trabajadas con esmero, son las rocas que siguieron el canto de Anfión. Otras cosas de este tipo se dicen de Orfeo: que los animales le seguían cuando tocaba la cítara ${ }^{58}$.

García-Gasco indica que Anfión es confundido con Orfeo en este pasaje y otros, debido a los poderes similares con la música que ambos ostentaban ${ }^{59}$. Lo curioso es que este poder de arrastrar rocas, único rasgo destacable de Anfión en su personalidad mítica, se le termina por atribuir a $\mathrm{Orfe}^{60}$. El poder de atraer a los animales y seres inanimados de Orfeo facilita la confusión ${ }^{61}$. Se destaca también la relación de Anfión con el oráculo de Bacis, otro aspecto similar al bardo.

Martín Hernández indica que la tradición que relaciona a Orfeo con la magia estaba bien asentada en el s. II d. C. ${ }^{62}$ y se extiende con el paso de los siglos. Esta relación proviene de la tradición que señala que Orfeo aprendió la magia de los Dáctilos del Ida, magos de alto rango ${ }^{63}$. Plinio el Viejo, en su Historia Natural, llega a indicar que posiblemente fue Orfeo quien expandió por Tesalia la magia:

Pensaría que Orfeo fue el primero en propagar por el territorio vecino esta superstición nacida en la medicina si Tracia, su patria, no hubiera carecido por completo de magia ${ }^{64}$.

La magia y la «diferencia» vuelven a ir de la mano; Plinio el Viejo, como romano, sabe que hay una distancia física y geográfica con el bardo y las tradiciones que se le atribuyen. Además Plinio posee un respeto por los magos ya que, pese a su actitud, dedica mucho de su escrito a discutir sobre las curaciones que dan a las enfermedades que aquejan a las gentes ${ }^{65}$. Plinio pone al bardo en el mismo plano que a Zoroastro, Circe, las Sirenas, Proteo, las hechiceras de Tesalia, los judíos, Pitágoras, Empédocles y Demócrito ${ }^{66}$.

Caso contrario ocurre con Apuleyo en su obra Apología, donde esta noción de «diferencia» relacionada con el término «mago» es mucho más palpable, ya que el mismo autor es víctima de las persecuciones y condena a muerte, que se realizaban en el s. II d. C., tanto a filósofos como a científicos acusados de usar magia. Los perseguidores se amparaban en la Lex Cornelia de sicariis et veneficis ${ }^{67}$ :

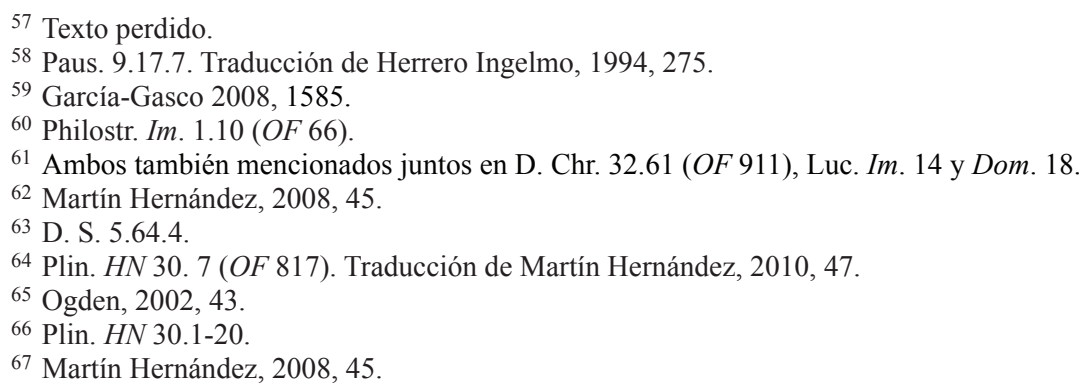


A los que estudian con mayor celo la providencia que rige el universo y rinden culto a los dioses con la profunda devoción, los llaman «magos» en el sentido vulgar de la palabra, como si fueran capaces de realizar por sí mismos lo que saben que tiene lugar, como sucedió antaño con Epiménides, Orfeo, Pitágoras y Ostanes ${ }^{68}$.

El que es considerado «diferente» pasó de ser un «ignorante» de las «buenas costumbres» a un ser «perverso» que posee un conocimiento religioso «falso» y que atenta contra el orden establecido. Lo más destacable en el testimonio de Apuleyo es que él no se considera un «mago» de la forma peyorativa en que quieren señalarlo, sino que se piensa como una persona con la devoción más profunda por la providencia y apunta además que personajes como Orfeo, Pitágoras, Epiménides y Ostanes, en el pasado, sufrieron el mismo trato.

En el texto de Apuleyo también se pone en relieve la ambivalencia de lo sagrado: los dos extremos creen estar en lo cierto, no pueden ver más allá del pensamiento binario, ni comprender que el fenómeno de lo religioso es uno solo. Todo se analiza desde el cristal con el que se mira. Como muchas cosas en la vida es una cuestión de perspectiva.

Orfeo también fue asociado con la práctica de la astrología, como indica Luciano:

Los griegos no recibieron ninguna noción de astrología ni de los etíopes ni de los egipcios, fue Orfeo, el hijo de Eagro y de Calíope el que los instruyó, pero no de una forma abierta y presentando su doctrina a la luz del día, sino bajo una forma mágica y mística conforme a su carácter ${ }^{69}$.

Se mira claramente lo voluble de las prácticas que eran asociadas al término de magia, en este caso la astrología. Se refleja por un lado el carácter secreto, de amplia significación y de «diferente» que poseía el término magia, y por otro lado, la poca claridad que existía en la Antigüedad en cuanto a su significado y lo que implicaba.

La tradición de Orfeo relacionada con la astrología, rasgo que no está descrito en las primeras manifestaciones del mito, sí estaba ampliamente extendida en la época imperial; el bardo era visto como toda una autoridad en el tema, a la altura de Hermes Trismegisto y Ostanes ${ }^{70}$.

Es importante señalar acerca de la tradición del bardo relacionada con la astrología, que a partir de la época romana se conocen obras de esta índole atribuidas a Orfeo, la primera de ellas es Dodecaeterides. Esta tradición se extendió de tal forma que en el s. XII el escritor bizantino Juan Tzetzes pensaba que Orfeo era el astrólogo más grande de la Antigüedad ${ }^{71}$.

${ }^{68}$ Apul. Apol. 27. Traducción de Martín Hernández, 2010, 45.

${ }^{69}$ Luc. De astr. 10 (OF 418). Traducción de Martín Hernández, 2010, 46.

${ }^{70}$ Martín Hernández, 2010, 76.

71 Tz. In Hes Op. 568 (278 Gaisford; OF 730). 
Esta tradición según West, seguido de Martín Hernández, debe remontarse incluso a la época helenística y en concreto, a los círculos pitagóricos interesados en astro$\operatorname{logía}^{72}$. Además la heterogeneidad de las tradiciones en torno al cantor se aprecia de manera clara, idea que contrasta con la opinión de Eliade que sostenía que el mito de Orfeo poseía una estructura primordial ${ }^{73}$.

Pausanias por su parte no cree en esta tradición, mas tampoco indica directamente que es falsa. Se podría señalar que existe un matiz en cuanto al empleo de la palabra «mago» por parte del Periegeta, que, si bien categoriza a Orfeo y a su arte de una manera inferior, no muestra una inquina con el personaje y sus seguidores, como la que expresa Platón o Estrabón. La distancia y el respeto que maneja Pausanias ante estas creencias parecen ser su modus operandi, en el que la distancia geográfica, filosófica $\mathrm{y}$ cultural posee un papel preponderante.

Smith indica que los antiguos estaban obsesionados con hacer distinciones en sus mitos, pero no en lo concerniente a lo sagrado propiamente, sino en cuanto a diferencias genealógicas y etiológicas. Sus más grandes creaciones culturales son sus objetos de reflexión, sus reglas, sus afinidades, sus intercambios y sus contaminaciones ${ }^{74}$.

El término «mago» toma su lugar dentro de esta obsesión con el sistema y su distinción, se vuelve un significante, un antes y un después en la geografía de la Antigüedad. Entonces: ¿Qué es lo que hace al mago y en este caso a Orfeo, relacionarse con lo caótico, con lo marginal, lo desestructurado y fuera de la ley?

Se podría deducir que Pausanias consideraba a Orfeo un extranjero del todo, pero si se tiene en cuenta que el objetivo del recorrido del Periegeta es una especie de «guía turística» de las ciudades griegas a las que intentaba darles relevancia, significa que de una manera u otra, consideraba a Orfeo como parte de su entorno cultural, lo que lleva nuevamente a decir que el bardo es parte del mundo de Pausanias, pero a la vez no lo es. Es tan griego como el Periegeta, pero diferente. La figura de Orfeo es doble: está en la polis y en sus alrededores.

\section{ORFEO, MUSEO Y LOS MISTERIOS DE ELEUSIS}

La relación de Orfeo con los Misterios de Eleusis y los misterios en general, está atestiguada por toda la Antigüedad ${ }^{75}$.

Con respecto a Museo, se puede indicar que es un personaje sin mitología que en muchas ocasiones es una imitación de Orfeo, al que, por conveniencia de la ciudad de Atenas, se le atribuyó una serie de noticias, textos y versos relacionados con lo que

72 West, 1983, 33; Martín Hernández, 2010, 76.

${ }^{73}$ Eliade, 1979, 219.

${ }^{74}$ Smith, 1978, 437.

75 Jiménez San Cristóbal, 2002, 419 n. 1432. 
se considera literatura órfica ${ }^{76}$. Dicho interés ateniense pretendió ligar al poeta Museo con Orfeo, para vincular míticamente la ciudad de Atenas con Tracia.

La aparición de figuras como la de Orfeo en zonas como Eleusis y el Ática, se debe posiblemente a la relación que mantuvieron los Pisistrátidas, antes y durante su tiranía, con la zona de Tracia desde el s. VI a. C., lo que indica que Atenas en ese momento histórico era un lugar con una gran efervescencia cultural y cultual, aunada a una proyección mítica rica y creativa de la ciudadanía ${ }^{77}$.

Orfeo y Museo comparten un rasgo fundamental: a los dos se les atribuye la autoría de poesía asociada a teogonías y rituales, características de la poesía órfica. Ambos poetas son llamados «teólogos» en algún momento de la tradición ${ }^{78}$.

Sí bien es cierto que Pausanias tenía una «diferencia» tanto filosófica como cultural con las tradiciones de Orfeo, no la tiene con las que hablan de Museo, como se observa en los siguientes pasajes:

En cuanto a hombres que dieron oráculos, dicen que fueron Euclo de Chipre, Museo, hijo de Antiofemo, y Lico, hijo de Pandión, atenienses; y de Beocia, Basis, inspirado por las ninfas. De todos estos, excepto Lico, he leído los oráculos.

Estos son las mujeres y los hombres que hasta mi tiempo se dice que han dado oráculos inspirados por el dios; pero en el largo curso del tiempo pueden aparecer otros con el mismo poder ${ }^{79}$.

Los atenienses convienen en que el desastre de Egospótamos les sucedió injustamente, pues fueron traicionados por los estrategos por dinero, y que Tideo y Adimanto fueron los que recibieron el dinero de Lisandro. Para probar esta historia citan la profecía de la Sibila:

Y entonces para los atenienses duelos lamentables dispondrá Zeus, que truena en lo alto del cielo, cuya fuerza es muy grande, con naves de guerra una batalla y un combate, destruidas de modo doloso por la cobardía de sus capitanes.

Y recuerdan otro de los oráculos de Museo:

$Y$, en efecto, contra los atenienses viene una salvaje lluvia por la vileza de sus jefes, pero algún consuelo habrá en la derrota; no pasarán inadvertidos en la ciudad y pagarán el castigo ${ }^{80}$.

Hay un poema entre los griegos, en versos hexamétricos, cuyo nombre es Eumolpia. Se atribuye a Museo, hijo de Antiofemo. En él se dice que el oráculo era común

\footnotetext{
${ }^{76}$ Martínez Nieto, 2008, 552.

77 Valdés Guía, 2008, 253.

${ }^{78}$ Martínez Nieto, 2008, 549.

79 Paus. 10.12.11. Traducción de Herrero Ingelmo, 1994, 376.

80 Paus. 10.9.11. Traducción de Herrero Ingelmo, 1994, 367-368.
} 
de Posidón y de Gea, que ella era la que daba oráculos y que Pircón era servidor de Posidón en los oráculos y profecías. Los versos son así:

En seguida Gea Ctonia pronunció una palabra sabia, y con ella Pircón, criado del ilustre que conmueve la Tierra.

Dicen que algún tiempo después Gea dio su parte a Temis, y que Apolo la recibió de Temis como un regalo. Dicen que a cambio del oráculo él a Posidón le dio Calauria, la que está enfrente de Trecén ${ }^{81}$.

Herrero Ingelmo, en su introducción a la Descripción de Grecia, indica que Pausanias tenía un gran respeto por lo divino, y que nunca puso en duda la existencia de los dioses en su obra ${ }^{82}$. Un ejemplo claro de esta afirmación se observa en el Libro I cuando describe a los atenienses.

Los atenienses tienen también en el ágora, entre otras cosas no conocidas de todos, un altar de Eleo, que es el más útil entre los dioses para la vida humana y las vicisitudes de la fortuna, y al que solo los atenienses entre los griegos le tributan culto; y no solo han instituido el amor a los hombres, sino que son piadosos con los dioses más que otros, $\mathrm{y}$, efectivamente, tienen un altar en honor de Aidos, de Feme y de Horme, y es muy claro que los que tienen más piedad que otros tienen una fortuna igual de equivalente ${ }^{83}$.

Se puede notar no solo el gran respeto que sentía Pausanias por los atenienses y sus valores, sino la importancia que tenía para él ser piadoso, ya que ello generaba una mejor calidad de vida. Pese a lo dicho por el autor, no se puede decir que tuviese en más alta estima las tradiciones atribuidas a Museo que las de Orfeo, porque nunca lo señala en sus textos, pero el contexto religioso que rodeaba a Museo era de mayor valía para el Periegeta que el del cantor, que era de Tracia.

Una opinión semejante a la de los atenienses tiene Pausanias de los beocios de Tanagra en el Libro IX, zona cercana a Eleusis:

A mí me parece que los de Tanagra son los que tienen mejores prácticas entre los griegos en el culto a los dioses, pues sus casas están a un lado y a otro de los santuarios por encima de ellas, en un lugar puro y lejos de los hombres ${ }^{84}$.

Se presenta esta cita debido a que es en esta misma zona donde el Periegeta realiza la mayor referencia a Orfeo en toda su obra ${ }^{85}$, lo que inclina a pensar de manera más definitiva que su «diferencia» con Orfeo no solo era cultural y filosófica,

\footnotetext{
${ }^{81}$ Paus. 10.5.6. Traducción de Herrero Ingelmo, 1994, 352-353.

${ }^{82}$ Herrero Ingelmo, 1994, 51-52.

83 Paus. 1.17.1. Traducción de Herrero Ingelmo, 1994, 45.

${ }^{84}$ Paus. 9.22.2. Traducción de Herrero Ingelmo, 1994, 284-285.

85 Paus. 9.30.4-12.
} 
sino también religiosa. Pausanias realiza la crítica a Orfeo dentro de la tierra donde, según su opinión, se tenían las mejores prácticas religiosas, lo miraba como un ser diferente dentro del organismo religioso de los Misterios de Eleusis en los que él era iniciado ${ }^{86}$.

Desde la visión de Pausanias, Museo parece representar una religiosidad más legítima que la de Orfeo. Orfeo, pese a ser griego, es observado como un personaje diferente y distante de las tradiciones propias de Eleusis. Pese a que se creía mayoritariamente que Orfeo era fundador de los misterios, Pausanias no compartía dicha visión y hace uso del concepto aristotélico de «diferencia» para dejarlo en evidencia.

\section{CONCLUSIONES}

Después del análisis de los textos, se puede establecer que el concepto de «diferencia» desempeñó un papel importante en la visión que tenía Pausanias sobre Orfeo por los siguientes motivos:

- Establece claramente que Orfeo, pese a ser griego, proviene de Tracia, lejos de las ciudades por las que el Periegeta transitaba con regularidad.

- Se sorprende por el aspecto de griego que posee Orfeo en la Lesque de Polignoto, ya que el atuendo más habitual con que aparecía en las representaciones era el oriental.

- Niega aspectos de la leyenda del cantor, como el descenso al Hades y su poder para domar a los animales, que eran creencias de la gente de su tiempo.

- Cataloga a Orfeo como «mago», concepto peyorativo para la época, que podía indicar que el bardo era poseedor de una teología y un conocimiento cosmológico inferior.

- Da una versión distinta del nacimiento de Orfeo, ya que desestima que Orfeo fuera hijo de la Musa Calíope e indica que es hijo de reyes. No posee entonces un origen semidivino, mas pertenece a la realeza, lo que deja claro la deuda con el evemerismo que tenía el Periegeta.

- Pausanias, al ser iniciado en los Misterios de Eleusis, indica que ninguna de las tradiciones que asociaban a Orfeo con la fundación de los misterios es cierta.

- Hace una diferencia entre el trato que recibe una figura propia de Atenas como Museo, con el que recibe Orfeo, proveniente de Tracia, del que niega prácticamente todas las tradiciones que se le atribuyen.

- Indica claramente que los atenienses y los beocios de Tanagra son los más piadosos y los que poseen las mejores prácticas religiosas respectivamente. A partir de esta afirmación se puede comprender el trato que realiza a la leyenda de Orfeo, donde niega lo que era creído mayoritariamente por los griegos de su época.

\footnotetext{
${ }^{86}$ Se abstrae de los pasajes Paus. 1.14.3, 1.38.7 y 4.33.5, la devoción que sentía el autor por las grandes diosas y se observa la reticencia de hablar acerca de lo que ocurría en las ceremonias mistéricas, señal inequívoca de que fue un iniciado.
} 
Lo que se abstrae de estos puntos es que Pausanias era una persona piadosa e iniciada en los Misterios de Eleusis y a partir de allí, establece una «diferencia» con la figura del bardo en el terreno de lo religioso, que lleva en paralelo a los ámbitos cultural, social y filosófico. Existe una simetría entre la distancia religiosa y la distancia cultural que sostiene Pausanias con Orfeo por ser el cantor de origen tracio. Ello fue posible, probablemente, por el carácter itinerante de Orfeo que, al trascender límites, permitió al autor generar una cara más al prisma del amplio mito del cantor. El concepto aristotélico de «diferencia», que en principio solo distinguía géneros, pudo ser llevado por Pausanias a los terrenos cultural, social, filosófico y religioso.

\section{BIBLIOGRAFÍA}

\section{FUENTES ANTIGUAS}

Aristóteles, Metafísica, ed. trilingüe de V. García Yebra, Madrid, 2012.

Diodoro de Sicilia, Biblioteca Histórica Libros IV-VIII (trad. de J. J. Torres Esbarranch), Madrid, 2004.

Estrabón, Geografia Libros V-VII, traducción y notas J. Vela Tejada, J. Gracia Artal, Madrid, 2001.

Pausanias, Descripción de Grecia, Trad. Esp. M. C. Herrero Ingelmo, 3 vols., Madrid, 1994.

Poetae Epici Graeci Testimonia et Fragmenta Pars II Fasc. 1-2 Orphicorum et Orphicis similium Testimonia et Fragmenta, ed. A. Bernabé, Monachii et Lipsiae, 2004-2005.

Poetae Epici Graeci Testimonia et Fragmenta Pars II Fasc. 3 Musaeus · Linus · Epimenides · Papyrus Derveni · Indices, ed. A. Bernabé, Berolini - Novi Eboraci, 2007.

\section{OBRAS DE REFERENCIA}

A. Bernabé, «Un 'resumen de historia del orfismo' en Strab. 7 fr. 18», Actas del X Congreso Español de Estudios Clásicos, vol. III, 2002, 59-66.

- «Tradiciones órficas en Diodoro» en EPIEIKEIA. Studia Graeca in memoriam Jesús Lens Tuero. M. Alganza Roldán. J. M. Camacho Rojo, P. P. Fuentes González \& M. Villena Ponsoda (edd.), Granada 2002a, 37-53.

- Platón y el orfismo. Diálogos entre religión y filosofía, Madrid, 2010.

- «Orfeo en Apolodoro», leído en el Simposi Internacional Apollodoriana: Antics Mites Noves Cueïlles, Barcelona, 2013, en prensa, al que he podido acceder por amabilidad del autor.

A. Bernabé, F. Casadesús, Orfeo y la Tradición Órfica: Un Reencuentro, Madrid, 2 vols., 2008.

J. N. Bremmer, «The Birth of the term 'Magic'» ZPE 126 (1999) 1-12 (actualizado en J. N. Bremmer, J. R. Veenstra [eds.], The Metamorphosis of Magic from Late Antiquity to the Modern Period, Leuven, 2003, 1-11, 267-273). 
W. Burkert, «Itinerant Diviners and Magicians: A Neglected Element in Cultural Contacts», en R. Hägg (ed.), The Greek Renaissance of the Eighth Century B.C. Tradition and Innovation, Stockholm, 1983, 115-119.

F. Casadesús, «Orfeo: el poder encantador de la música y la palabra», http://www.liceus.com/ cgi-bin/aco/culc/mit/08400.asp [acceso: 24.10.2012].

M. Eliade, «Orfeo, Pitágoras y la nueva escatología» en Historia y creencias de las Ideas Religiosas II, traducción de J. Valiente Malla, Barcelona, 1979, 217-250.

W. Freiert, «Orpheus: A Fugue on the Polis» en D. C. Pozzi - J. M. Wickersham (eds.), Myth and the Polis, Ithaca (New York), 1991, 32-48.

R. García-Gasco Villarubia, «Orfeo y el orfismo en las Dionisíacas de Nono» en Bernabé Casadesús (eds.) 2008, 1575-1602.

R. Gordon, «Imagining Greek and Roman Magic» en V. Flint, R. Gordon, G. Luck, D. Ogden (eds.), The Athlone History of Witchcraft and Magic in Europe, vol. II, Ancient Greece and Rome, 1999, 159-275.

F. Graf, «Orpheus: A poet among men» en J. Bremmer (ed.), Interpretations of Greek Mythology, London-Sidney, 1987, 80-106.

W. Hutton, «The Construction of Religious Space in Pausanias» en J. Elsner - I. Rutherford (eds.), Pilgrimage in Graeco-Roman \& Early Christian Antiquity Seeing the Gods, Oxford, 2005, 291-317.

A. I. Jiménez San Cristóbal, Rituales Órficos, Tesis doctoral, Madrid, 2002 (versión online: http://biblioteca.ucm.es/tesis/fll/ucm-t25949.pdf).

I. M. Linforth, The Arts of Orpheus, Berkeley-Los Angeles, 1941 (Reimpr. New York, 1973).

S M. Macías, Orfeo y el orfismo en Eurípides, Tesis doctoral, Madrid, 2008 (versión online: http://eprints.ucm.es/8091/.

R. Martín Hernández, «Rasgos Mágicos en el mito de Orfeo» en Bernabé - Casadesús, 2008, 75-90.

- Orfeo y los magos. La literatura órfica, la magia y los misterios, Madrid, 2010.

R. Martínez Nieto, «Otros poetas griegos próximos a Orfeo» en Bernabé - Casadesús 2008, 549-578.

R. Olmos, «Imágenes de un Orfeo fugitivo y ubicuo» en Bernabé - Casadesús 2008, 137-178.

C. Padilla «Hombres divinos y taumaturgos en la Antigüedad. Apolonio de Tiana» en A. Piñero (ed.), En la Frontera de lo Imposible, Madrid, 1997, 141-160.

I. Rutherford, «Tourism and the Sacred: Pausanias and the Traditions of Greek Pilgrimage» en S. F. Alocock, J. F. Cherry, J. Esner, (eds.), Pausanias: Travel and Memory in Roman Greece, Oxford, 2001, 40-52.

J. Z. Smith, «Towards Interpreting Demonic Powers in Hellenistic and Roman Antiquity», ANRW II. 16. 1, Berlin-New York, 1978, 425-439.

M. Valdés Guía, «La revalorización de la Tierra y de la 'autoctonía' en la Atenas de los Pisistrátidas: el nacimiento de Erictonio y de Dioniso órfico» en Gerión 28.1 (2008) 235254. 